\title{
Person-environment fit, flourishing and intention to leave in universities of technology in South Africa
}

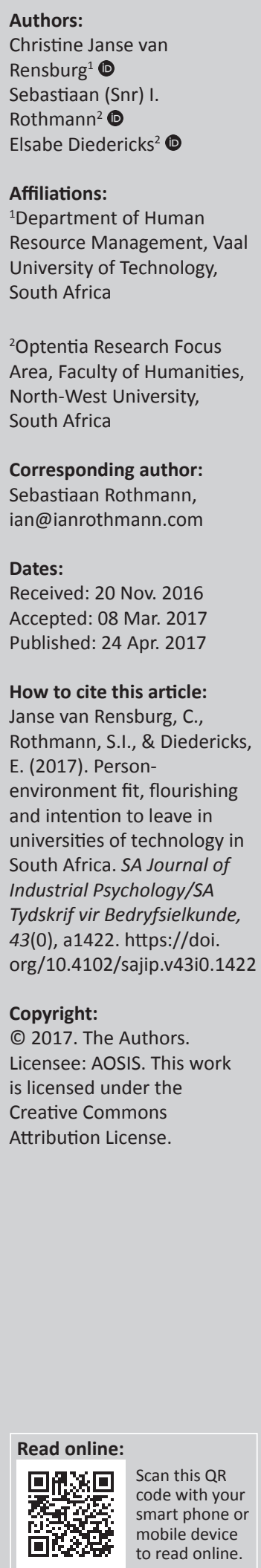

Orientation: Retaining staff is vital to ensure that universities accomplish their missions. To optimise the potential of staff members and retain staff, it is necessary to study their flourishing and fit in their jobs and organisations.

Research purpose: The aim of this study was to investigate the relationship between personenvironment fit, flourishing at work and intention to leave.

Motivation for the study: Research is needed to validate a measure of flourishing at work. Outcome variables such as intention to leave have not been studied in relation to flourishing at work. Moreover, it is necessary to study antecedents of flourishing at work, such as personenvironment fit.

Research approach, design and method: A cross-sectional survey design was used with a convenience sample of 339 academic employees from three universities of technology in South Africa. Three perceived fit scales, the Flourishing-at-Work Scale (FAWS) and the Turnover Intention Scale were administered.

Main findings: Findings supported a three-factor model of flourishing at work, consisting of emotional, psychological and social well-being. The highest mean frequencies on flourishing dimensions were obtained for competence and emotional engagement. The lowest mean frequencies were obtained for relatedness and social well-being. Person-environment fit predicted intention to leave, both directly and indirectly, via flourishing. The findings support the internal consistency and validity of the FAWS.

Practical/managerial implications: Managers and human resource practitioners should consider the use of a multidimensional measure to assess flourishing at work. Considering certain dimensions of well-being at work (e.g. work engagement and competence of employees) without considering other dimensions (e.g. job satisfaction, affect balance and meaning at work) will not be sufficient to assess and promote the subjective well-being of employees.

Contribution/value-add: This study contributes to knowledge regarding the reliability and validity of a measure of flourishing at work. It confirms that person-environment fit has a strong positive effect on flourishing of employees and a strong negative effect on their intentions to leave.

\section{Introduction}

The academic environment in South African higher education institutions, and specifically universities of technology (UoTs), has been affected by significant restructuring and transformation (Du Pré, 2009). These changes have had adverse effects on the morale of staff. Higher Education South Africa (HESA) has confirmed that it is currently facing challenges in retaining key and talented academic staff (HESA, 2011) because of the 'brain drain' phenomenon where staff members leave to other sectors. Retaining staff is vital to ensure that universities accomplish their visions and missions, and become centres of excellence ( $\mathrm{Ng}^{\prime}$ ethe, Iravo \& Namusonge, 2012). Academics who are not flourishing may decide to resign (Theron, Barkhuizen \& Du Plessis, 2014). In order to optimise the potential of staff members and retain staff, it is necessary to study their flourishing and fit in their jobs and organisations.

Flourishing describes subjective well-being, which focuses on how individuals evaluate their experiences in different contexts. The notion of subjective well-being emerged during the 1950s and initially focused squarely on hedonic or emotional well-being, such as happiness, life satisfaction or affect balance (Diener, 1984). Later, the two aspects of psychological well-being (Ryff, 1989) and social well-being (Keyes, 1998) were incorporated, also known as eudaimonic well-being. 
The Mental Health Continuum (MHC) and the Mental Health Continuum-Short Form (MHC-SF) were developed to measure these well-being components, also known as flourishing (Keyes, 2002, 2009). Keyes (2005) conceptualised flourishing in life as a multidimensional perspective of emotional well-being (feeling well) and psychological and social well-being (functioning well). Rothmann (2013) extended these concepts to the work context.

Research is needed regarding flourishing at work. A study by Rothmann (2013) identified a framework for flourishing at work, while a study by Rautenbach (2015) validated a scale, the Flourishing-at-Work Scale (FAWS), which measures flourishing at work. Although the factorial validity and reliability of the FAWS were confirmed by Rautenbach (2015), the relations of the measuring instrument to individual and organisational outcomes were not studied. Therefore, more research is needed to validate the FAWS. Intention to leave and flourishing at work were previously studied in relation to flourishing in life (Diedericks, 2012; Swart, 2012). Hence, the aim of this study was to analyse the reliability and validity of the FAWS by exploring not only its psychometric properties but also its relations with person-environment (P-E) fit and intentions to leave.

\section{Flourishing at work}

Psychological studies increasingly use the concept of flourishing to describe well-being and/or hedonic and eudaimonic components of happiness (Seligman, 2011). Flourishing is a state in which individuals experience emotional well-being, psychological and social well-being (Keyes \& Annas, 2009). Flourishing can be linked to several theoretical models that conceptualise flourishing aspects through research done by Keyes (2002), Diener et al. (2010), Seligman (2011), Huppert and So (2013), and Noble and McGrath (2015), as indicated in Table 1.

Keyes (2002, 2007) developed the MHC. Individuals' wellbeing on the MHC vary from flourishing, to moderately mentally healthy, to languishing. Languishing individuals experience low levels of emotional, psychological and social well-being. Moderately mentally healthy individuals are neither flourishing nor languishing. Flourishing individuals experience high levels of emotional, psychological and social well-being. Keyes (2009) developed the MHC-SF, a brief questionnaire which allows individuals to rate frequency of occurrence of the three well-being components.

Other researchers also conceptualised flourishing and developed measures of flourishing. For example, Diener et al. (2010) conceptualised flourishing in terms of selfperceived success regarding relationships, self-esteem, purpose and optimism. They developed a one-dimensional scale (consisting of eight items) to measure flourishing.

Seligman (2011) conceptualised flourishing in terms of five dimensions in the PERMA model: positive emotions $(\mathrm{P})$, engagement $(\mathrm{E})$, relationships $(\mathrm{R})$, meaning $(\mathrm{M})$, and accomplishment (A). In line with the MHC, the PERMA model suggests that well-being consists of feeling and functioning dimensions. The PERMA-profiler was created to provide a brief measure of the five well-being dimensions (Forgeard, Jayawickreme, Kern \& Seligman, 2011).

Huppert and So (2013) conceptualised flourishing in terms of positive emotions, positive characteristics (including emotional stability, vitality, optimism, resilience and selfesteem) and positive functioning (including engagement, competence, meaning and positive relationships). In their PROSPER model, Noble and McGrath (2015) suggested that positivity $(\mathrm{P})$, relationships $(\mathrm{R})$, outcomes $(\mathrm{O})$, strengths $(\mathrm{S})$, purpose $(P)$, engagement $(E)$ and resilience $(R)$ are essential elements of flourishing in educational contexts. Although the above-mentioned models suggest important dimensions of flourishing, they were not developed for work contexts.

Rothmann (2013) extended the MHC of Keyes (2002, 2005) to the work context. He suggested that flourishing is a multidimensional concept that includes dimensions of both feeling well (i.e. emotional well-being) and functioning well

TABLE 1: Five conceptualisations of flourishing.

\begin{tabular}{llll}
\hline Keyes & Diener et al. & Seligman et al. & Huppert and So \\
\hline Positive & Positive & Positive & Positive \\
Relationships & Relationships & Relationships & Relationships \\
Positive affect & Engagement & Engagement & Engagement \\
Purpose in life & Purpose and meaning & Meaning and purpose & Meaning \\
Self-acceptance & Self-acceptance and & Positive emotion & Self-esteem \\
Positive affect & Self-esteem & Accomplishment & Positive emotion \\
Social contribution & Competence & - & Competence \\
Social integration & Optimism & - & Optimism \\
Social actualisation & Social contribution & - & Emotional \\
Social acceptance & - & - & Stability \\
Social coherence & - & - & Vitality \\
Environmental mastery & - & - & Resilience \\
Personal growth & - & - & - \\
Autonomy & - & - & Strengths \\
Life satisfaction & - & - & - \\
\hline
\end{tabular}


(i.e. psychological and social well-being) in work contexts. Emotional well-being consists of job satisfaction and a positive affect balance and was conceptualised based on the research of Keyes $(2002,2005)$ and Rojas and Veenhoven (2013). Psychological well-being consists of autonomy, competence, relatedness, learning (personal growth), meaning and purpose, and engagement. Theoretical justification of these dimensions came from Deci and Ryan (2011), Frankl (1992), Kahn and Heaphy (2014), Keyes (2002), Ryff (1989), Seligman (2011), Spreitzer, Lam and Fritz (2010), and Steger, Dik and Duffy (2012). Social well-being refers to experiences focused on social tasks that are encountered in organisations (Keyes, 1998).

Concerning emotional well-being, job satisfaction relates to employees' perceptions of all aspects of their current jobs in relation to their wants and expectations. Positive affect in the work environment refers to pleasant experiences such as joy, gratitude, serenity, hope, pride and amusement. Negative affect refers to unpleasant emotions experienced in the work context, because of events such as anger, sadness, anxiety, boredom, frustration and guilt. Subsequently, the most salient affective experiences affect work life through need gratification (Rojas \& Veenhoven, 2013).

The self-determination theory (Deci \& Ryan, 2011; Ryan, Huta \& Deci, 2008) provides a theoretical justification for the inclusion of three psychological needs individuals have: autonomy, competence and relatedness. The need for autonomy concerns the desire to experience freedom of choice when making decisions. Competence (referred to as environmental mastery in the model of Ryff, 1989) refers to the individual's inherent desire to control outcomes and to experience mastery in an environment. Relatedness indicates the need to connect to others, to interact with them and to care for others. The concept of learning is included based on the concepts of 'personal growth' in the psychological well-being model of Ryff (1989) and 'learning' in the model of thriving (Spreitzer et al., 2010). Individuals experience learning when they sense that they are acquiring and applying the knowledge and skills they need to do their work. Meaning and purpose at work can be viewed as employees' subjective experiences that their work is significant, valuable and purposeful (May, Gilson \& Harter, 2004; Steger et al., 2012). Work engagement refers to employees' connections to work (Kahn \& Heaphy, 2014), investing their energies in role behaviours and expressing themselves in roles by exhibiting authenticity (Rothbard \& Patil, 2012). Work engagement consists of a cognitive component (being alert at work, feeling absorbed and involved in one's work), an emotional component (being dedicated and connected to one's work and colleagues, and experiencing a sense of worth) and a physical component (being physically involved in a task and displaying energy) (Kahn, 1990; Kahn \& Heaphy, 2014).

Five features described social well-being in the work context (Rautenbach, 2015) based on Keyes' (2005) conceptualisation of social well-being in life: (1) Social acceptance refers to a positive attitude towards and acceptance of diversity;
(2) Social growth signifies whether individuals believe in the potential of development of colleagues, groups and organisations; (3) Social contribution refers to whether individuals think that their daily actions add value to the organisation and others; (4) Social coherence indicates whether employees find their institutions and social lives meaningful and understandable; (5) Social integration reveals whether employees are experiencing a sense of relatedness, comfort and support from the organisation.

In summary, flourishing at work consists of three dimensions: emotional, psychological and social well-being. Emotional well-being consists of positive affect, negative affect and job satisfaction. Psychological well-being consists of autonomy, competence, relatedness, learning, meaning and purpose, and engagement. Social well-being consists of social acceptance, social growth, social contribution, social coherence and social integration.

\section{Person-environment fit, flourishing and intention to leave}

Person-environment fit can be defined as the compatibility between employees and the environments in which they find themselves (Kristof-Brown \& Guay, 2011). Edwards (2008) describes the theoretical foundations of P-E fit in the organisational context through the matching model of career decision-making of Parson (1909), the need-press model of Murray's $(1938,1951)$ and Lewin's $(1935,1951)$ field theory. P-E fit is considered as a multidimensional construct as individuals experiencing fit are simultaneously nested in multiple aspects of an environment (Kristof-Brown \& Guay, 2011). Therefore, several levels of fit have been specified, such as the fit between persons and the entire organisation or their group or their job (Su, Murdock \& Rounds, 2015). The current research focuses on these three types of fit in the organisational context, namely, person-organisation fit (P-O fit), persongroup fit (P-G fit) and person-job fit (P-J fit).

$\mathrm{P}-\mathrm{O}$ fit is defined as the correspondence between personal goals and values of employees and the goals, norms and values of their organisation (Su et al., 2015). If people experience this correspondence, a perception of social inclusion and intention to stay emerges (Van Vianen, Stoelhorst \& De Goede, 2013). P-G fit entails the compatibility between the values, goals, personality and interpersonal styles of employees and their work groups (Su et al., 2015). P-G fit includes interdependence (i.e. the extent to which employees are required to work together) and social interactions (i.e. workbased relationships) (Glew, 2012). P-J fit refers to the congruence between employees' personal characteristics and their job characteristics. P-J fit includes demands-abilities fit and needsupplies fit. Demands-abilities fit occurs when employees have the knowledge, skills and abilities to meet the demands of their jobs. Needs-supplies fit occurs when a job satisfies an employee's needs (Kristof-Brown \& Guay, 2011).

According to P-E fit theory, well-being of individuals is affected by their interactions with their environments, as well as the 
match between individual characteristics (e.g. knowledge, abilities, skills, needs and values) and environmental characteristics (e.g. role characteristics, organisational values and structures) (Shipp \& Jansen, 2011). Research by Schneider (1987) and Su et al. (2015) showed that people perform better and remain in organisations that match their personal characteristics.

Research by Kristof-Brown and Billsberry (2013) has shown that P-E fit is positively associated with favourable work attitudes and behaviours (e.g. job satisfaction and performance) and negatively associated with unfavourable outcomes (e.g. organisational withdrawal and turnover). Gabriel, Diefendorff, Chandler, Moran and Greguras (2014) found that $\mathrm{P}-\mathrm{O}$ fit and P-J fit relate positively to positive affect and job satisfaction, and negatively to negative affect in the work environment.

Johnson, Taing, Chang and Kawamoto (2013) state that a selfregulation process underlies the attainment of fit. Through action identification, individuals become aware of and connect to their jobs. The connection with their jobs gives meaning and purpose in the work context (Dik, Byrne \& Steger, 2013). According to Van Vianen et al. (2013), people experience a fundamental need to belong and therefore develop collaborative relationships with others to become socially included; thus defining natural $\mathrm{P}-\mathrm{O}$ fit outcomes in terms of relatedness and social integration.

Studies (Diedericks \& Rothmann, 2014; Seligman, 2011) showed that higher levels of positive emotions, engagement, meaning, positive relations and social well-being are negatively related to intention to leave. Intention to leave refers to an employee's decision or choice to leave an organisation to seek a position elsewhere (Theron et al., 2014).

\section{Aim and hypotheses}

This study implies that P-E fit can influence flourishing at work and can impact intention to leave via flourishing at work:

H1: Emotional well-being, psychological well-being and social well-being load on one factor (namely, flourishing vs. languishing).

H2: P-E fit predicts flourishing at work.

H3: Flourishing at work inversely predicts intention to leave.

H4: P-E fit relates negatively to intention to leave.

H5: P-E fit indirectly affects intention to leave via flourishing.

\section{Research design}

\section{Research approach}

A descriptive, cross-sectional and quantitative approach was followed (De Vos, Strydom, Fouché \& Delport, 2011). Questionnaires were utilised to gather data regarding P-E fit, flourishing and turnover intention of academic employees.

\section{Participants}

A total of 339 employees were recruited from three UoTs in Gauteng and the Free State. The response rate was 23\%. Most participants (91.4\%) were on the levels from junior lecturer to senior lecturer, and the largest group (50.9\%) comprised lecturers. Most of the participants (85\%) were permanently appointed.

General biographical characteristics of the participants are described in Table 2. This table shows that a total of $46.2 \%$ of the sample were males, while $53.8 \%$ were females. The ages of the participants ranged from 24 to 74 years. The largest group of the participants comprised married (71.4\%), white South Africans (64.6\%) and those who spoke Afrikaans (56.3\%).

The results in Table 2 show that almost half of the respondents $(43.7 \%)$ held a master's degree, while most respondents $(67.3 \%)$ had served more than 5 years in an academic profession.

\section{Measuring instruments}

Three perceived fit scales from Greguras and Diefendorff (2009) were applied to determine P-E fit aspects of P-O fit, P-G fit and P-J fit. The FAWS (Rautenbach, 2015) was used to measure flourishing at work, and questions from the Turnover Intention Scale (TIS; Sjöberg \& Sverke, 2000) were utilised to measure intention to leave.

$P$-E fit questions from three perceived fit scales from Greguras and Diefendorff (2009) were used. Three items of P-O fit (e.g. 'My personal values match my organisation's values and culture'), P-G fit (e.g. 'The things I value in life are similar to

\begin{tabular}{|c|c|c|c|}
\hline Item & Category & Frequency & $\%$ \\
\hline \multirow[t]{3}{*}{ Gender } & Male & 156 & 46.0 \\
\hline & Female & 182 & 53.7 \\
\hline & Missing & 1 & 0.3 \\
\hline \multirow[t]{5}{*}{ Age (years) } & 24 to 35 & 69 & 20.4 \\
\hline & 36 to 45 & 115 & 33.9 \\
\hline & 46 to 55 & 92 & 27.1 \\
\hline & 56 to 65 & 56 & 16.5 \\
\hline & 66 to 74 & 7 & 2.1 \\
\hline \multirow[t]{3}{*}{ Home language } & Afrikaans & 191 & 56.3 \\
\hline & English & 65 & 19.2 \\
\hline & African language & 83 & 24.5 \\
\hline \multirow[t]{6}{*}{ Highest qualification } & Diploma & 4 & 1.2 \\
\hline & Postgraduate diploma & 8 & 2.4 \\
\hline & Degree & 44 & 13.0 \\
\hline & Honour's degree & 27 & 8.0 \\
\hline & Master's degree & 148 & 43.6 \\
\hline & Doctoral degree & 108 & 31.8 \\
\hline \multirow[t]{6}{*}{ Tenure (years) } & Less than 5 & 111 & 32.7 \\
\hline & 5 to 10 & 99 & 29.2 \\
\hline & 11 to 15 & 66 & 19.4 \\
\hline & 16 to 20 & 37 & 11 \\
\hline & 21 to 25 & 20 & 5.9 \\
\hline & More than 25 & 6 & 1.8 \\
\hline
\end{tabular}


the things my co-workers value') and P-J fit (e.g. 'The match is very good between the demands of my job and my personal skills') measured how well employees perceive their abilities to fit with these aspects. The reliability of these scales was between $\alpha=0.82$ and $\alpha=0.88$. All the fit items were rated on a five-point scale ranging from 1 (not at all) to 5 (completely).

The FAWS (Rautenbach, 2015) consists of 40 questions which measured the three dimensions of flourishing (emotional, psychological and social well-being) in the work context. The respondents had to answer questions regarding the frequency with which they experienced specific symptoms during the past month. Emotional well-being consists of three dimensions, namely, positive affect (three items, e.g. 'How often did you feel grateful?'), negative affect (three items, e.g. 'How often did you feel bored?'), and job satisfaction (two items, e.g. 'How often did you feel real enjoyment of your work?'). Psychological well-being consists of nine dimensions, namely, autonomy satisfaction (three items, e.g. 'How often did you feel you can be yourself at your job?'), competence satisfaction (three items, e.g. 'How often did you feel that you really master your tasks at your job?'), relatedness satisfaction (three items, e.g. 'How often did you really connect with other people at your job?'), learning (three items, e.g. 'How often did you find that you are developing a great deal as a person?'), meaning and purpose (six items, e.g. 'How often did you feel that you sense what makes your job worthwhile?'), cognitive engagement (three items, e.g. 'How often did you concentrate a lot on your work?'), emotional engagement (three items, e.g. 'How often did you feel passionate about your job?'), physical engagement (three items, e.g. 'How often did you feel energised when you work?') and social well-being (five items, e.g. 'How often did you feel you had something important to contribute to your organisation?'). Responses were measured on a six-point scale ranging from 1 (never) to 6 (every day). Confirmatory factor analysis (CFA) was performed (Rautenbach, 2015) and the scale reliability ranged from $p=0.74$ to 0.94 .

A slightly modified version of the TIS (Sjöberg \& Sverke, 2000) was utilised to measure intention to leave. The adapted TIS consists of three items (e.g. 'I frequently think of quitting my job'), and a 0.83 Cronbach alpha coefficient was reported. Response options ranged from 1 (strongly disagree) to 5 (strongly agree).

\section{Data analysis}

Mplus 7.4 (Muthén \& Muthén, 1998-2016) and SPSS23 (IBM Corp, 2016) were used to analyse the data. The maximum likelihood estimation with robust standard errors (MLR) was used as an estimator. Various indices were used to assess model fit for measurement and structural models, namely: (1) absolute fit indices: the chi-square statistic, standardised root mean residual (SRMR), root mean square error of approximation (RMSEA); and (2) incremental fit indices: the Tucker-Lewis index (TLI) and comparative fit index (CFI) (West, Taylor \& Wu, 2012). TLI and CFI values higher than
0.90 indicate acceptable fit of a model to the data. RMSEA and SRMR values lower than 0.08 indicate a close fit between the model and the data. Furthermore, the Akaike information criterion (AIC) and Bayes information criterion (BIC) were used to compare alternative measurement models. The AIC is a comparative measure of fit and is meaningful when one estimates different models. The lowest AIC indicates the best-fitting model. The BIC provides an indication of model parsimony (Kline, 2010). Scale reliability $(\rho)$ was computed using the procedure suggested by Raykov (2009).

\section{Research procedure}

The researcher contacted the managements of three UoTs in Gauteng and the Free State and obtained permission and ethical clearance to conduct the study. Ethical clearance was also obtained from the Ethics Committee at the university from where the research was undertaken (Ethics number: NWU-HS-2014-0126). The researcher administered the online electronic questionnaire in English via the myresearchsurvey. com platform. A cover letter explaining the purpose of the study and emphasising the confidentiality and anonymity of the research project accompanied the survey. Participation in the project was voluntary, and respondents had the option to withdraw at any time. Participants completed an online questionnaire from the end of August until mid-October 2015. Responses to the items were captured in an Excel spreadsheet; thereafter, it was converted to an SPSS data set for analysis.

\section{Results \\ Testing the measurement model}

Four measurement models were tested using CFA.

Model 1 consisted of three latent variables: P-E fit, flourishing at work and intention to leave. P-E fit consisted of three firstorder latent variables: P-O fit (measured by three items), P-G fit (measured by three items) and P-J fit (measured by three items). Flourishing at work consisted of three first-order latent variables: emotional, psychological and social well-being. Emotional well-being was divided into three second-order latent variables: positive affect (measured by three items), negative affect (measured by three items) and job satisfaction (measured by two items); psychological well-being consisted of eight second-order latent variables: autonomy satisfaction (measured by three items), competence satisfaction (measured by three items), relatedness satisfaction (measured by three items), learning (measured by three items), meaning and purpose (measured by six items), cognitive engagement (measured by three items), emotional engagement (measured by three items), physical engagement (measured by three items) and social well-being (measured by four items). Intention to leave was measured by three items. All the latent variables in model 1 were allowed to correlate.

Model 2 followed the same template as model 1, except that all the flourishing at work items of emotional well-being loaded on a single latent variable (measured by eight items), 
psychological well-being loaded on a single latent variable (measured by 27 items) and social well-being loaded on a single latent variable (measured by four items). Model 3 followed the same template, but the flourishing at work items consisted of two latent variables: hedonic well-being (feeling well) and eudaimonic well-being (functioning well). Hedonic well-being was divided into three second-order latent variables: positive affect (measured by three items), negative affect (measured by three items) and job satisfaction (measured by two items). Eudaimonic well-being consisted of two second-order latent variables: psychological wellbeing (measured by 27 items) and social well-being (measured by four items). Model 4 followed the same template, but all the items loaded on three latent variables: P-E fit (measured by nine items), flourishing at work (measured by 39 items) and intention to leave (measured by three items).

Table 3 shows the fit statistics for the competing measurement models.

AIC and BIC fit statistics were used, in addition to other fit indices in this study, to compare alternative measurement models. Although the AIC and BIC values of model 3 were the lowest, they were not significantly different from the values of model 1. For theoretical reasons, as well as in the interest of parsimony, it was decided to use model 1 (AIC = 45468.60, $\mathrm{BIC}=46145.80)$.

\section{Model development}

The analysis continued in an exploratory mode to improve the fit of model 1. Based on modification indices (MIs), two items, items 18 ('Feel you had something important to contribute to your organisation?') and 38 ('Devote a lot of energy to your job?'), from the FAWS were removed because they significantly reduced the model fit. The fit statistics for the first adapted model (model 1.2) were as follows: $\mathrm{AIC}=43483.90$, $\mathrm{BIC}=$ 44138.15. Although the fit of model 1.2 improved $(\triangle \mathrm{AIC}=$ $1984.70, \Delta \mathrm{BIC}=2007.65)$, the MI (89.10) for the error covariance of items 30 ('Feel your work helps you make sense of the world around you?') and 31 ('Feel that your work helps you to better understand yourself?') indicated that the fit of model 1.2 could be improved. In model 1.3, the errors of items 30 and 31 were allowed to correlate. The AIC and BIC values for model 1.3 were as follows: $\mathrm{AIC}=43376.91, \mathrm{BIC}=44034.98$. A large error covariance ( $\mathrm{MI}=56.37$ ) was indicated for items 23 ('Find yourself learning often?') and 24 ('Find that you continue to learn more as time goes by?'). In model 1.4, the errors of items 23 and 24 were also allowed to correlate. The AIC and BIC values for model 1.4 improved slightly, as follows: AIC = 43312.15, BIC $=43974.05$. In the final model, the MI (26.57) for the error covariance of items 8 ('Experience real enjoyment in your work?') and 9 ('Feel free to express your ideas and opinions in your job?') indicated that the model fit could be improved by allowing an error correlation between the two items. The fit statistics for model 1.5 further improved as follows: $\mathrm{AIC}=43281.88, \mathrm{BIC}=43947.61$. Hence, Hypothesis 1 is accepted.

The relationship between each manifest variable and its respective latent variable was statistically significant $(p<0.01)$. Therefore, the posited relationships among indicators and constructs were established (Hair, Black, Babin \& Andersen, 2010).

\section{Descriptive statistics and correlations of the scales}

Table 4 shows the reliabilities and correlations for the scales.

The results showed that respondents scored high on P-J fit (mean $=4.09 ; \mathrm{SD}=0.69)$ but low on P-G fit (mean = 2.98; $\mathrm{SD}=$ $0.94)$ and $\mathrm{P}-\mathrm{O}$ fit $($ mean $=2.98 ; \mathrm{SD}=0.91)$, which reflect a perception that individuals fit with their jobs but not with organisations and groups they are working in. Table 4 shows scale reliabilities range from 0.58 to 0.94 . The reliability of the P-J fit scale was somewhat lower than the prescribed value but still above 0.55 and sufficiently acceptable for basic research (Nunnally, 1978). The other scales have acceptable internal consistencies (Raykov, 2009).

Figure 1 shows the mean scores of the total sample on the 12 dimensions of flourishing over the last month.

Figure 1 shows that the lowest scores were obtained on relatedness and social well-being. Although a low score was also obtained on negative affect, it should be noted that negative affect is on a reversed scored scale. The highest scores were obtained on competence and emotional engagement. Concerning intention to leave, approximately $25 \%$ of the responses were received on scales 4 and 5 , which indicate that almost a quarter of the respondents had intentions to leave their organisation.

\section{Testing the structural model}

The structural model was tested based on the measurement model. Table 5 gives an account of the fit statistics and

\begin{tabular}{|c|c|c|c|c|c|c|c|c|c|}
\hline \multirow[t]{2}{*}{ Model } & \multirow[t]{2}{*}{$\chi^{2}$} & \multirow[t]{2}{*}{$d f$} & \multirow[t]{2}{*}{ TLI } & \multirow[t]{2}{*}{ CFI } & \multicolumn{2}{|c|}{ RMSEA } & \multirow[t]{2}{*}{ SRMR } & \multirow[t]{2}{*}{ AIC } & \multirow[t]{2}{*}{ BIC } \\
\hline & & & & & Estimate & $90 \%$ Cls & & & \\
\hline 1 & 2726.20 & 1253 & 0.87 & 0.88 & $0.06 *$ & $0.056,0.062$ & 0.09 & 45468.60 & 46145.80 \\
\hline 2 & 4263.75 & 1265 & 0.80 & 0.74 & $0.08^{*}$ & $0.081,0.086$ & 0.10 & 47335.59 & 47966.88 \\
\hline 3 & 2718.20 & 1252 & 0.88 & 0.87 & $0.06 *$ & $0.056,0.062$ & 0.09 & 45461.14 & 46142.17 \\
\hline 4 & 4825.02 & 1268 & 0.70 & 0.69 & $0.09 *$ & $0.088,0.094$ & 0.09 & 48026.15 & 48645.97 \\
\hline
\end{tabular}


Table 4: Reliability coefficients and correlations of the scales $(n=339)$.

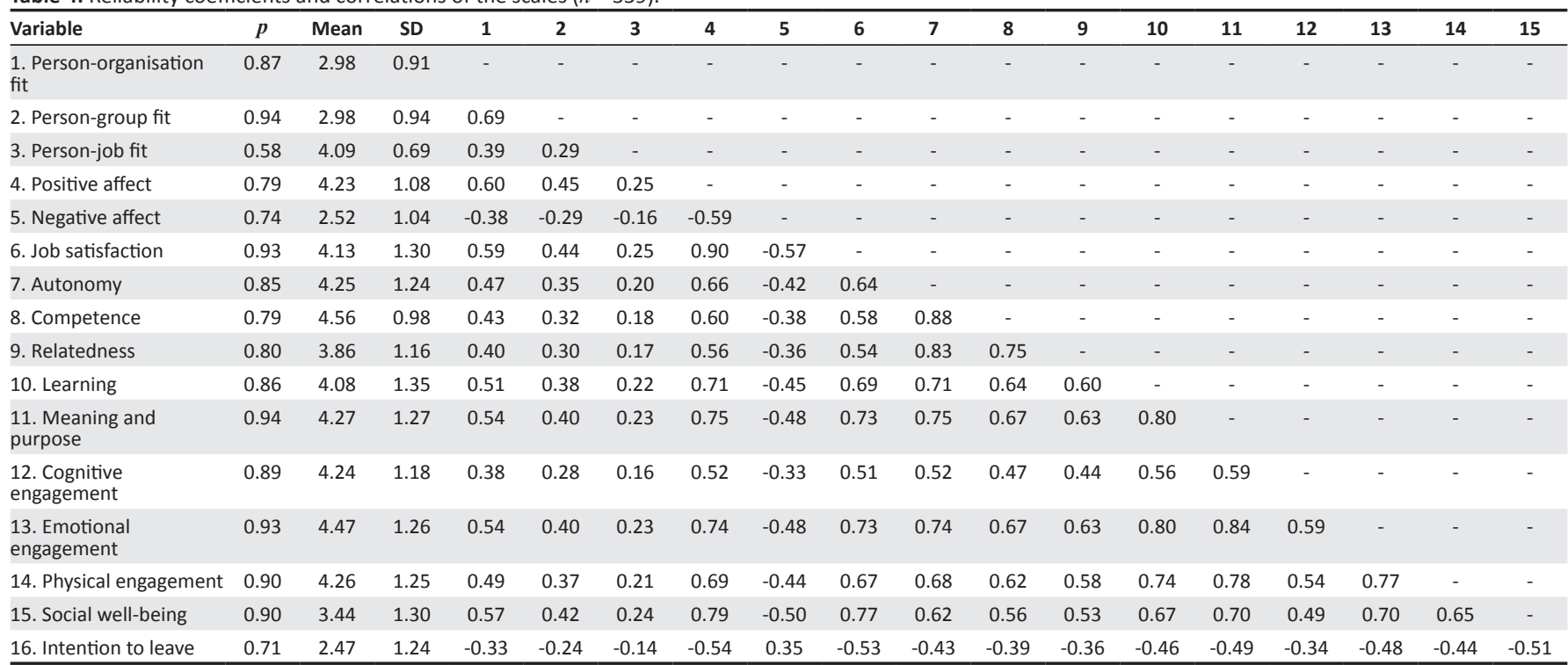

Note: All correlations are statistically significant $(p<0.01)$.

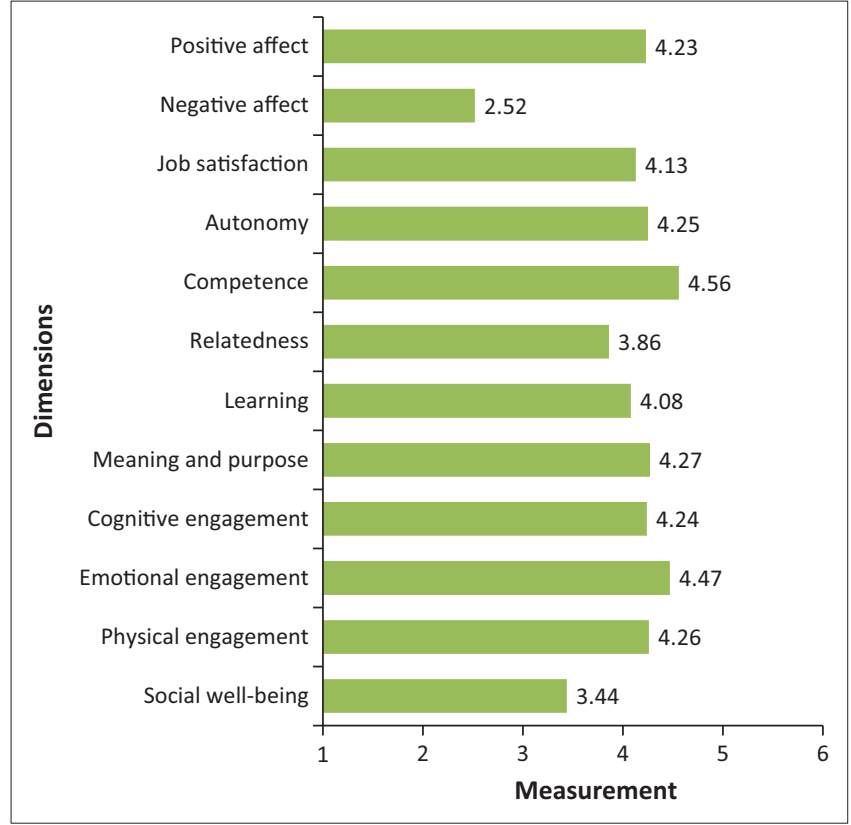

FIGURE 1: Mean scores on 12 dimensions of flourishing.

standardised regression coefficients for the three competing structural models. The final measurement model showed a chi-square value of 2169.45 and the best-fitting structural model showed a chi-square value of 2169.45 . There was no difference between the chi-square of the best-fitting measurement and structural models, which suggests that the model specification was acceptable.

This model yielded the following fit statistics: $\chi^{2}=2169.45$, $\mathrm{df}=1151 ; p<0.001 ; \mathrm{TLI}=0.91 ; \mathrm{CFI}=0.91 ; \mathrm{RMSEA}=0.05$ (90\% CI 0.048, 0.054); SRMR $=0.08$. These statistics show a good fit for the hypothesised model. Given the crosssectional nature of the data, another model was tested (see Table 5). Model 2 (the direct effects model) included paths from P-E fit to flourishing and intention to leave. However, the path from flourishing to intention to leave was
TABLE 5: Fit indices and standardised path coefficients of the structural models.

\begin{tabular}{llll}
\hline Measures & Variable & $\begin{array}{l}\text { Direct effects } \\
\text { (model 2) }\end{array}$ & $\begin{array}{l}\text { Direct and indirect } \\
\text { effects (model 1) }\end{array}$ \\
\hline Fit indices & $\chi^{2}$ & $2226.29 *$ & $2167.07^{*}$ \\
& $d f$ & 1152 & 1151 \\
& TLI & 0.90 & 0.91 \\
& CFI & 0.91 & 0.91 \\
& RMSEA & 0.05 & 0.05 \\
& RMSEA 90\% CI & $0.049,0.056$ & $0.048,0.054$ \\
& SRMR & 0.08 & 0.08 \\
& AIC & 43342.85 & 43281.88 \\
& BIC & 44004.74 & 43947.61 \\
Direct effects of P-E fit & Flourishing & $0.81^{*}$ & $0.69 *$ \\
Direct effects of flourishing & Intention to leave & - & $-0.68^{*}$ \\
Direct effects of P-E fit & Intention to leave & $-0.51^{*}$ & 0.13 \\
\hline
\end{tabular}
$*, p<0.01$.

$\chi^{2}$, chi-square statistic; $d f$, degrees of freedom; TLI, Tucker-Lewis index; CFI, comparative fit index; RMSEA, root mean square error of approximation; SRMR; standardised root mean square residual; AIC, Akaike information criterion; BIC, Bayes information criterion; P-E, person-environment

constrained to zero. The following changes in chi-square $\left(\Delta \chi^{2}\right)$ were found: Models 1 and $2\left(\Delta \chi^{2}=33.69, \Delta d f=1\right.$, $p<0.001)$. Table 5 shows the standardised path coefficients estimated by Mplus for the hypothesised model. Figure 2 shows the structural model.

Next, the obtained relations of the best-fitting and most parsimonious structural model (model 1) are discussed regarding the hypotheses of this study.

For the portion of the model predicting flourishing at work, the path coefficient of P-E fit ( $\beta=0.68, p<0.06)$ was statistically significant and had the expected sign. P-E fit therefore predicts flourishing at work. Hypothesis 2 is accepted.

For the portion of the model predicting intention to leave, the path coefficient of flourishing $(\beta=-0.59, p<0.08)$ was statistically significant and had the expected sign. Flourishing predicts intention to leave. Hypothesis 3 is accepted. 


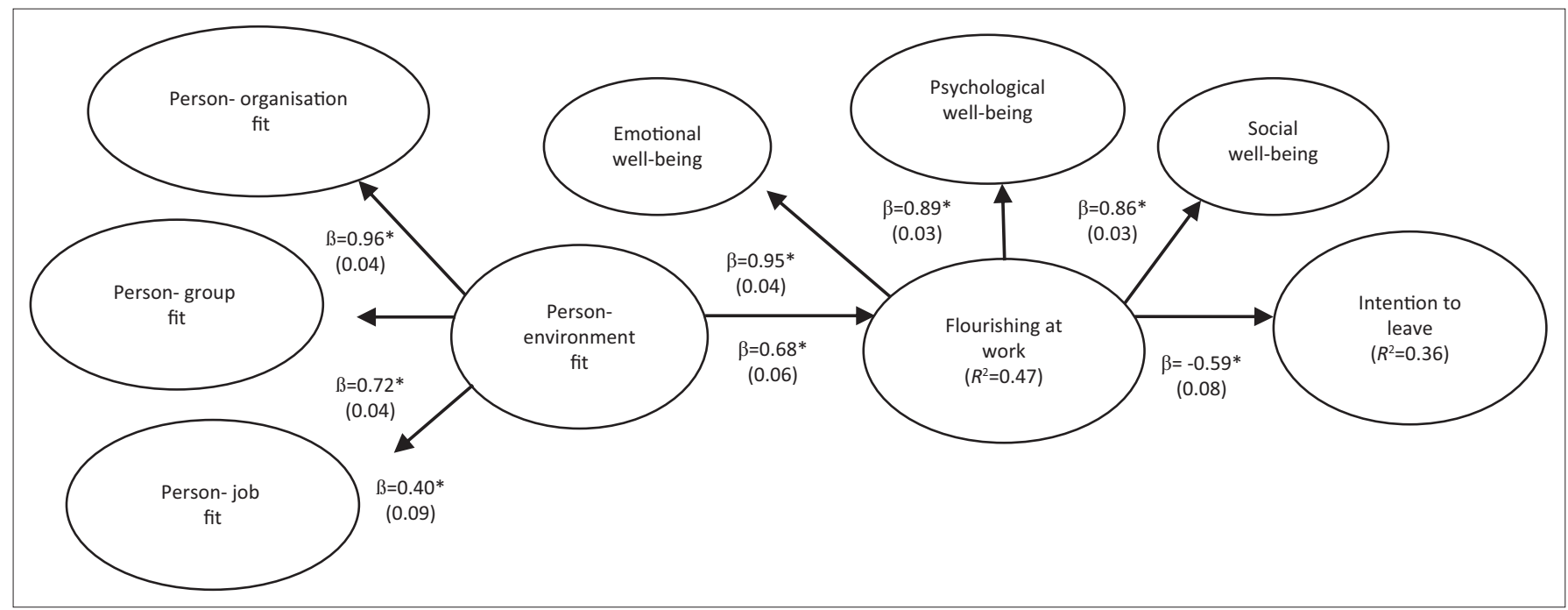

Note: All regression coefficients are statistically significant $\left({ }^{*}, p<0.01\right)$.

FIGURE 2: The structural model (standardised solution with standard errors in parentheses).

\section{Indirect effects}

Hayes's (2013) procedure was followed to investigate the indirect effect of P-E fit on intentions to leave. Bootstrapping (with 10000 samples) was used to construct two-sided biascorrected $95 \%$ confidence intervals (CIs) to evaluate indirect effects. The indirect effect was $-0.47(-0.65,-0.34)$ and shows that the P-E fit had a significant negative effect on intention to leave via flourishing at work. Hypotheses 4 and 5 are supported.

In terms of the effect sizes (Cohen, 1988), the indirect effects model accounts for the following percentages of the variance: P-E fit explained $47 \%$ of the variance in flourishing, which shows that the P-E fit has a large influence on flourishing. Flourishing explained $36 \%$ of the variance for intention to leave, which confirms that a lack of flourishing (i.e. languishing) does have a large effect on the tendency of individuals to leave organisations.

\section{Discussion}

The aim of this study was to investigate the relationship between P-E fit, flourishing at work and intention to leave. The results confirmed the internal consistency and construct validity of the long form of a measure of flourishing at work. The results provided support for a model in which P-E fit predicted flourishing at work, which in turn predicted intention to leave. P-E fit had a large effect on flourishing. A lack of flourishing had a large effect on the tendency of individuals to leave organisations.

The multidimensional perspective of flourishing at work confirmed the inclusion of the feeling well (emotional wellbeing) and functioning well (psychological and social wellbeing) dimensions, as adopted in the model of Keyes (2005). A three-factor model of flourishing at work was found to be superior to the one- and two-factor models. This finding corresponds with the findings of Rautenbach (2015) supporting the three well-being dimensions of the FAWS.
These results support the construct validity of the FAWS. The reliabilities of the flourishing dimension scales were acceptable $(p>0.70)$, except for the subscale that measures negative affect. Thus, the FAWS provided a useful assessment of self-reported flourishing at work.

Findings revealed that almost a quarter of academics had intentions to leave their organisation. The loss of human capital might hold severe cost and productivity implications for these institutions (Son, Kim \& Kim, 2014). The manifestation of intention to leave by academics, the socalled brain drain, was found in studies in higher education (Theron et al., 2014). The results of this study supported the multidimensionality of the scale which was used to measure P-E fit. P-O fit was strongly related to P-G fit, while P-J fit was moderately related to P-O fit and P-G fit. Unexpectedly, the reliability of P-J fit subscale was lower than the guidelines of 0.70 .

P-E fit predicted a large percentage of the variance in flourishing. Therefore, individuals who perceived that they fit into their work and organisational environment were more inclined to feel and function well. Previous studies (Dik et al., 2013; Gabriel et al., 2014; Kristof-Brown \& Billsberry, 2013; Van Vianen et al., 2013) also showed that dimensions of P-E fit had a close connection to the dimensions of flourishing at work. Su et al. (2015) found that people who perceive a fit between their personal goals and the organisation goals are motivated towards positive behaviours and career outcomes. These positive behaviours and career outcomes support flourishing at work and might, therefore, be seen to play a bigger role in defining P-E fit. Results showed that academics who feel that they fit in their organisations are also individuals who experience positive affect, feel satisfied with their jobs, experience meaning, purpose and emotional engagement in work and their social well-being is higher. The results showed that the P-O and P-G contributed more to explaining the variance in P-E fit than P-J fit. However, the poor reliability of the P-J fit subscale probably contributed to this finding. 
Academics who feel they fit with their group members experienced positive affect, job satisfaction and social wellbeing. These results concurred with findings on experiences of employees in previous studies (Dik et al., 2013; Gabriel et al., 2014; Johnson et al., 2013; Van Vianen et al., 2013).

Flourishing at work predicted a large percentage of variance in intention to leave, which suggests that employees who do not flourish might think of leaving their organisations. This result is supported by findings that low intentions to leave are explained by flourishing at work (Diedericks \& Rothmann, 2014; Swart \& Rothmann, 2012). The current challenges in retaining key and talented academic staff (HESA, 2011) can thus be addressed by focusing on the increment of flourishing behaviour.

\section{Limitations of the study}

The study had several limitations. Firstly, self-reports were used to gather data, which might cause inflated results. This is especially true for the relation between PE fit and flourishing. Future studies could consider alternatives for self-reports of fit assessment, such as co-worker and supervisor ratings. Secondly, the sample was restricted to three UoTs in the Free State and Gauteng, and therefore external generalisation cannot be made from this study. Thirdly, given the cross-sectional design of the study, it was not possible to study the stability of flourishing over time. Lastly, only one item was used to measure each facet of social well-being in this study. Future studies should include at least three items per facet (Kline, 2010). Although most of the findings were encouraging and an important step towards understanding the nature of flourishing at work, more research is needed in different organisational environments. Work-related factors associated with the flourishing of employees should be investigated, and intervention programmes should be developed and implemented to promote flourishing in the work context.

\section{Managerial implications and recommendations}

This study showed that relationships between P-E fit, flourishing at work and intention to leave do exist. The fact that $\mathrm{P}-\mathrm{O}$ and $\mathrm{P}-\mathrm{G}$ fit showed high results in relation to flourishing gives an indication that human resource practitioners and industrial psychologists should consider interventions focusing on the promotion of P-O and P-G fit in order to increase flourishing of employees, which will in turn curb intentions to leave.

Interventions to address fit aspects should focus on recruitment and selection practices to ensure that the right person is appointed in the right job, provide substantial coaching and orientation programmes for newly appointed staff to create a sense of belonging and engagement, and initiate diversity training workshops to provide a better perspective and understanding of differences between people.
Flourishing-specific interventions of employees could focus on the implementation of training programmes to enhance personal growth and development, provide counselling opportunities, initiate resilience training, and build and promote positive social relationships. By promoting healthy social relations, social well-being in the environment will enable employees to positively contribute to individual, group and organisational success. Coupled with the theoretical perspectives, the belief is that there is compelling evidence to show that efforts to improve fit on organisational and group levels, as well as to enrich social well-being, will enhance P-E fit and flourishing at work. Consequently, higher levels of flourishing at work will reduce intentions to leave.

\section{Conclusion}

The study confirmed the reliability and validity of a multidimensional scale which measures well-being at work on a continuum from flourishing to languishing. Flourishing at work is strongly related to P-E fit, specifically the P-O fit dimension. P-E fit and subjective well-being (expressed on a continuum from flourishing to languishing) strongly predicted intentions to leave the organisation.

\section{Acknowledgements}

The authors would like to thank Thuthuka of the National Research Foundation (NRF) and the Vaal University of Technology for the funding of the article.

\section{Competing interests}

The authors declare that they have no financial or personal relationship(s) which may have inappropriately influenced them in writing this article

\section{Authors' contributions}

The authors contributed equally to this project.

\section{References}

Cohen, J. (1988). Statistical power analysis for the behavioral sciences (2nd edn.). Hillsdale, NJ: Lawrence Erlbaum Associates.

Deci, E.L., \& Ryan, R.M. (2011). Levels of analysis: Regnant causes of behaviour and well-being: The role of psychological needs. Psychological Inquiry, 22, 17-22. https://doi.org/10.1080/1047840X.2011.545978

De Vos, A.S., Strydom, H., Fouché, C.B., \& Delport, C.L.S. (2011). Research at grass roots (4th edn.). Vanderbijlpark, South Africa: Van Schaik.

Diedericks, E. (2012). Flourishing of employees in the information technology industry in South Africa. Unpublished doctoral thesis, North-West University, Vanderbijlpark, South Africa.

Diedericks, E., \& Rothmann, S. (2014). Flourishing of information technology professionals: Effects on individual and organisational outcomes. SA Journal of Business Management, 45(1), 27-41.

Diener, E. (1984). Subjective well-being. Psychological Bulletin, 95, 542-575. https:// doi.org/10.1037/0033-2909.95.3.542

Diener, E., Wirtz, D., Tov, W., Kim-Prieto, C., Choi, D.W., Oishi, S., et al. (2010). New well-being measures: Short scales to assess flourishing and positive and negative feelings. Social Indicators Research, 97(2), 143-156. https://doi.org/10.1007/ s11205-009-9493-y

Dik, B.J., Byrne, Z.S., \& Steger, M.F. (2013). Purpose and meaning in the workplace. Washington, DC: American Psychological Association.

Du Pré, R. (2009). The place and role of universities of technology in South Africa. Bloemfontein, South Africa: South African Technology Network. 
Edwards, J.R. (2008). Person-environment fit in organizations: An assessment of theoretical progress. The Academy of Management Annals, 2, 167-230. https:// theoretical progress. The Academy of
doi.org/10.1080/19416520802211503

Forgeard, M.J.C., Jayawickreme, E., Kern, M., \& Seligman, M.E.P. (2011). Doing the right thing: Measuring wellbeing for public policy. International Journal of Wellbeing, 1(1), 79-106.

Frankl, V.E. (1992). Man's search for meaning (4th edn.). Boston, MA: Beacon Press.

Gabriel, A.S., Diefendorff, J.M., Chandler, M.M., Moran, C.M., \& Greguras, G.J. (2014) The dynamic relationships of work affect and job satisfaction with perceptions of fit. Personnel Psychology, 67(2), 389-420. https://doi.org/10.1111/peps.12042

Glew, D.J. (2012). Effects of interdependence and social interaction-based person-team fit. Administrative Sciences, 2(1), 26-46. https://doi.org/10.3390/admsci2010026

Greguras, G.J., \& Diefendorff, J.M. (2009). Different fits satisfy different needs: Linking person-environment fit to employee commitment and performance using selfdetermination theory. Journal of Applied Psychology, 94(2), 465-477. https://doi. org/10.1037/a0014068

Hair, J.F., Black, W.C., Babin, B.J., \& Andersen, R.E. (2010). Multivariate data analysis: A global perspective. Upper Saddle River, NJ: Pearson.

Hayes, A.F. (2013). Introduction to mediation, moderation, and conditional process analysis: A regression-based approach. New York: The Guilford Press.

Higher Education South Africa (HESA). (2011). A generation of growth: Proposal for a national programme to develop the next generation of academics for South African higher education. Pretoria, South Africa: University of South Africa.

Huppert, F.A., \& So, T.T.C. (2013). Flourishing across Europe: Application of a new conceptual framework for defining well-being. Social Indicators Research, 110 837-861. https://doi.org/10.1007/s11205-011-9966-7

IBM Corp. (2016). IBM SPSS statistics: Version 23. Chicago, IL: IBM Corporation.

Johnson, R.E., Taing, M.U., Chang, C., \& Kawamoto, C.K. (2013). A self-regulation approach to person-environment fit. In A.L. Kristof-Brown \& J. Billsberry (Eds.), Organizational fit: Key issues and new directions (pp. 74-98). Malden, MA: Wiley.

Kahn, W.A. (1990). Psychological conditions of personal engagement and disengagement at work. Academy of Management Journal, 33, 692-724. https:// doi.org/10.2307/256287

Kahn, W.A., \& Heaphy, E.D. (2014). Relational contexts of personal engagement at work In C. Truss, R. Delbridge, E. Soane, K. Alfes, \& A. Shantz (Eds.), Employee engagement in theory and practice (pp. 82-96). Abingdon, United Kingdom: Routledge.

Keyes, C.L.M. (1998). Social well-being. Social Psychology Quarterly, 61, 121-140. https://doi.org/10.2307/2787065

Keyes, C.L.M. (2002). The mental health continuum: From languishing to flourishing in life. Journal of Health and Social Behavior, 43, 207-222. https://doi. org/10.2307/3090197

Keyes, C.L.M. (2005). Mental illness and/or mental health? Investing axioms of the complete state model of health. Journal of Consulting and Clinical Psychology, 73 539-548. https://doi.org/10.1037/0022-006X.73.3.539

Keyes, C.L.M. (2007). Promoting and protecting mental health as flourishing: A complementary strategy for improving national mental health. American Psychologist, 62, 95-108. https://doi.org/10.1037/0003-066X.62.2.95

Keyes, C.L.M. (2009). Brief description of the Mental Health Continuum Short Form (MHC-SF). Retrieved March 16, 2017, from https://www.aacu.org/sites/default/ files/MHC-SFEnglish.pdf 16 March 2017

Keyes, C.L.M., \& Annas, J. (2009). Feeling good and functioning well: Distinctive concepts in ancient philosophy and contemporary science. Journal of Positive Psychology, 4, 197-201. https://doi.org/10.1080/17439760902844228

Kline, R.B. (2010). Principles and practice of structural equation modeling (3rd edn.) New York: Guilford Press.

Kristof-Brown, A.L., \& Billsberry, J. (2013). Fit for future. In A.L. Kristof-Brown \& J. Billsberry (Eds.), Organizational fit: Key issues and new directions (pp. 1-18). Malden, MA: Wiley.

Kristof-Brown, A.L., \& Guay, R.P. (2011). Person-environment fit. In S. Zedeck (Ed.), APA handbook of industrial and organizational psychology - Volume 3 (pp. 3-50). Washington, DC: APA.

Lewin, K. (1935). A dynamic theory of personality. New York: McGraw-Hill.

Lewin, K. (1951). Field theory in social science. New York: Harper

May, D.R., Gilson, R.L., \& Harter, L.M. (2004). The psychological conditions of meaningfulness, safety and availability and the engagement of the human spirit at work. Journal of Occupational and Organizational Psychology, 77, 11-37. https:// doi.org/10.1348/096317904322915892

Muthén, L.K., \& Muthén, B.O. (1998-2016). Mplus users' guide (7th edn.). Los Angeles, CA: Muthén \& Muthén.

Murray, H.A. (1938). Explorations in personality. Boston, MA: Houghton Mifflin.

Murray, H.A. (1951). Toward a classification of interaction. In T. Parsons \& E.A. Shils (Eds.), Toward a general theory of action (pp. 434-464). Cambridge, MA: Harvard University Press.
Ng'ethe, J.M., Iravo, M.E., \& Namusonge, G.S. (2012). Determinants of staff retention in public universities in Kenya: Empirical review. International Journal of Humanities and Social Science, 2(13), 105-212.

Noble, T., \& McGrath, H. (2015). PROSPER: A new framework for positive education Psychology of Well-being, 5(2), 1-17. https://doi.org/10.1186/s13612-0150030-2

Nunnally, J.C. (1978). Psychometric theory (2nd edn.) New York: McGraw-Hill.

Parsons, F. (1909). Choosing a vocation. Boston, MA: Houghton Mifflin.

Rautenbach, C. (2015). Flourishing of employees in a fast moving consumable goods environment. Unpublished doctoral thesis, North-West University, Vanderbijlpark, South Africa.

Raykov, T. (2009). Interval estimation of revision effect on scale reliability via covariance structure analysis. Structural Equation Modeling, 16, 539-555. https:// doi.org/10.1080/10705510903008337

Rojas, M., \& Veenhoven, R. (2013). Contentment and affect in the assessment of happiness. Social Indicators Research, 110, 415-431. https://doi.org/10.1007/ s11205-011-9952-0

Rothbard, N.P. \& Patil, S.V. (2012). Being there: Work engagement and positive organizational scholarship. In K.S. Cameron \& G.M. Spreitzer (Eds.), The Oxford
handbook of positive organizational scholarship (pp. 56-68). New York: Oxford handbook

Rothmann, S. (2013). From happiness to flourishing at work: A Southern African perspective. In M.P. Wissing (Ed.), Well-being research in South Africa: Cross-
cultural advances in positive psychology - Volume 4 (pp. 123-151). Dordrecht, cultural advances in positive
The Netherlands: Springer.

Ryan, R.M., Huta, V., \& Deci, E.L. (2008). Living well: A self-determination theory perspective on eudaimonia. Journal of Happiness Studies, 9, 139-170. https://doi. org/10.1007/s10902-006-9023-4

Ryff, C.D. (1989). Happiness is everything, or is it? Explorations on the meaning of psychological well-being. Journal of Personality and Social Psychology, 57, 1069-1081. https://doi.org/10.1037/0022-3514.57.6.1069

Schneider, B. (1987). The people make the place. Personnel Psychology, 40(3), 437-453. https://doi.org/10.1111/j.1744-6570.1987.tb00609.x

Seligman, M.E.P. (2011). Flourish: A visionary new understanding of happiness and well-being - And how to achieve them. London, United Kingdom: Nicolas Brealey.

Shipp, A.J., \& Jansen, K.J. (2011). Reinterpreting time in fit theory: Crafting and recrafting narratives of fit in medias res. Academy of Management Review, 36(1), 76-101. https://doi.org/10.5465/amr.2009.0077

Sjöberg, A., \& Sverke, M. (2000). The interactive effect of job involvement and organisational commitment on job turnover revisited: A note on the mediatin role of turnover intention. Scandinavian Journal of Psychology, 3, 247-252. https://doi.org/10.1111/1467-9450.00194

Son, S., Kim, D.Y., \& Kim, M. (2014). How perceived interpersonal justice relates to job burnout and intention to leave: The role of leader-member exchange and cognition-based trust in leaders. Asian Journal of Social Psychology, 17(1), 12-24. https://doi.org/10.1111/ajsp.12038

Spreitzer, G.M., Lam, C.F., \& Fritz, C. (2010). Engagement and human thriving: Complimentary perspectives on energy and connections to work. In A.B. Bakker \& M.P. Leiter (Eds.), Work engagement: A handbook of essential theory and research (pp. 132-146). New York: Psychology Press.

Steger, M.F., Dik, B.J., \& Duffy, R.D. (2012). Measuring meaningful work: The Work and Meaning Inventory (WAMI). Journal of Career Assessment, 20, 322-337. https:// doi.org/10.1177/1069072711436160

Su, R., Murdock, C.D., \& Rounds, J. (2015). Person-environment fit. In P.J. Hartung, M.L. Savickas, \& W.B. Walsh (Eds.), APA handbook of career interventions (pp. 81-89). Washington, DC: American Psychological Association.

Swart, J., \& Rothmann, S. (2012). Authentic happiness of managers, and individual and organisational outcomes. South African Journal of Psychology, 42, 492-508. https://doi.org/10.1177/008124631204200404

Swart, J.P. (2012). Antecedents and outcomes of happiness of managers in the agricultural sector in South Africa. Unpublished doctoral thesis, North-West University, Vanderbijlpark, South Africa.

Theron, M., Barkhuizen, N., \& Du Plessis, Y. (2014). Managing the academic talent void: Investigating factors in academic turnover and retention in South Africa. SA Journal of Industrial Psychology, 40(1), 1-14. https://doi.org/10.4102/sajip. v40i1.1117

Van Vianen, A.E.M., Stoelhorst, J.W., \& De Goede, M.E.E. (2013). The construal of person-organization fit during the ASA stages. In A.L. Kristof-Brown \& J. Billsberry (Eds.), Organizational fit: Key issues and new directions (pp. 145-169). Malden, MA: Wiley.

West, S.G., Taylor, A.B., \& Wu, W. (2012). Model fit and model selection in structura equation modeling. In R.H. Hoyle (Ed.), Handbook of structural equation modeling (pp. 209-231). New York: The Guilford Press. 